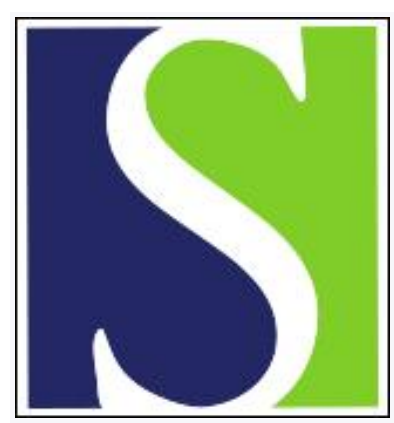

Scand J Work Environ Health 1986;12(1):61-65

https://doi.org/10.5271/sjweh.2182

Issue date: Feb 1986

Prevalence of probable kerosene dermatoses among ball-bearing factory workers.

by Jee SH, Wang JD, Sun CC, Chao YF

This article in PubMed: www.ncbi.nlm.nih.gov/pubmed/2938252

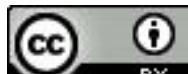




\title{
Prevalence of probable kerosene dermatoses among ball-bearing factory workers
}

\author{
by Shiou-Hwa Jee, MD, ${ }^{1}$ Jung-Der Wang, MD, ScD, ${ }^{2}$ Chee-Ching Sun, MD, ${ }^{3}$ Yung-Fa Chao, MD1
}

\begin{abstract}
JEE S-H, WANG J-D, SUN C-C, CHAO Y-F. Prevalence of probable kerosene dermatoses among ballbearing factory workers. Scand J Work Environ Health 12 (1986) 61-65. The objective of this study was to investigate the prevalence rate of dermatoses among workers in a ball-bearing factory and its possible association with their exposure to kerosene. Two groups of female workers participated in the study. The first group included 79 persons with major kerosene exposure during work, while the second, a reference group, was composed of 263 zipper-manufacturing workers with a similar age distribution, educational background, and income. Dermatologic examinations were used to determine the prevalence rate of hand dermatoses (erythema, scaling, and eczema). In the exposed group 51 persons $(65 \%)$ had erythema with or without desquamation over the interdigital spaces, 12 persons $(15 \%)$ had eczematous lesions, 3 persons $(4 \%)$ had defatting dermatitis, and only 13 persons $(16 \%)$ were apparently asymptomatic. In the reference group only one person had hand eczema $(<1 \%)$. The difference in the occurrence of dermatoses between the two groups was significant according to the Mantel-Haenszel summary chi-square test. Patch tests on five workers with eczematous lesions revealed one to be sensitive to mercury. The findings indicate that kerosene is a skin irritant. Antirust oil used on the ball-bearings may also contribute to the irritant effect.
\end{abstract}

Key terms: ball-bearing factory, irritant dermatitis.

In 1981, a ball-bearing factory in Taiwan requested consultation concerning dermatologic problems in their assembling department, where workers often complained of burning, pain, edema, and blister formation on the hands. The situation had been present since the factory opened in 1966 . The study objective was to investigate the prevalence rate and clinical signs of dermatoses among workers with kerosene exposure and to determine the possible nature of kerosene dermatitis.

\section{Subjects and methods}

Work process and exposures

A typical ball-bearing is made of a roller sandwiched between inner and outer rings, and the roller is composed of balls moving in two jointd separators (figure 1).

The work process is as follows (figure 2): In process A, the steel rings are washed with kerosene and antirust oil, the suitably sized inner and outer rings are screened and paired by machine, and the paired rings are transported to a tank and washed under a kerosene shower.

1 Department of Dermatology, Mackay Memorial Hospital, Taipei, Taiwan, Republic of China.

2 Institute of Public Health, National Taiwan University, College of Medicine, Taipei, Republic of China.

${ }^{3}$ Department of Dermatology, National Taiwan University Hospital, Taipei, Taiwan, Republic of China.

Reprint requests to: Dr S-H Jee, Department of Dermatology, Mackay Memorial Hospital, No 92, Section 2, ChungSan North Road, Taipei, Taiwan, Republic of China.
In process $B$, bare-handed workers insert steel balls into the rings (figure 3 ) and shake the product to check the degree of tightness; separators are then placed between the rings to distance the balls evenly, the two separators being joined by machine; and the completed products are again transported to a kerosene tank and washed under a pressure ejector. The products emerge hot and heavily coated with kerosene. In process C, workers wearing gloves check the outline of the products and then use a sound instrument to check the quality. In process $\mathrm{D}$, the products are dried at room temperature and sealed by grease. After further checking with a sound instrument, the product is packaged.

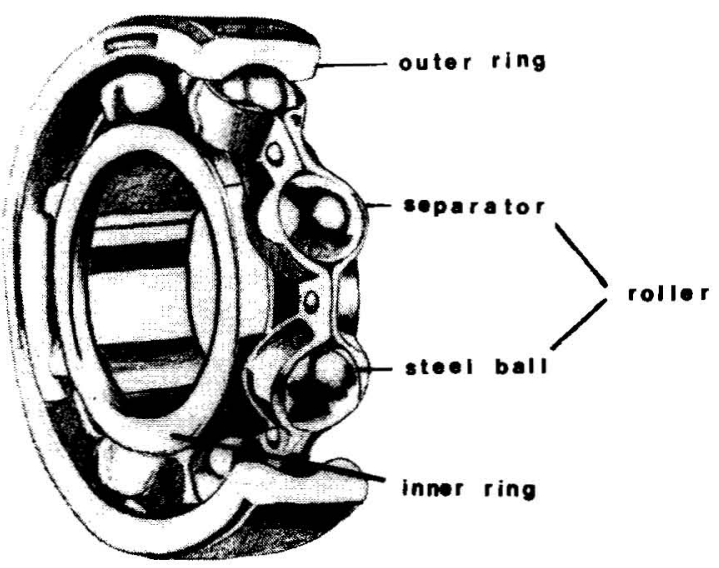

Figure 1. Structure of a typical ball-bearing. 


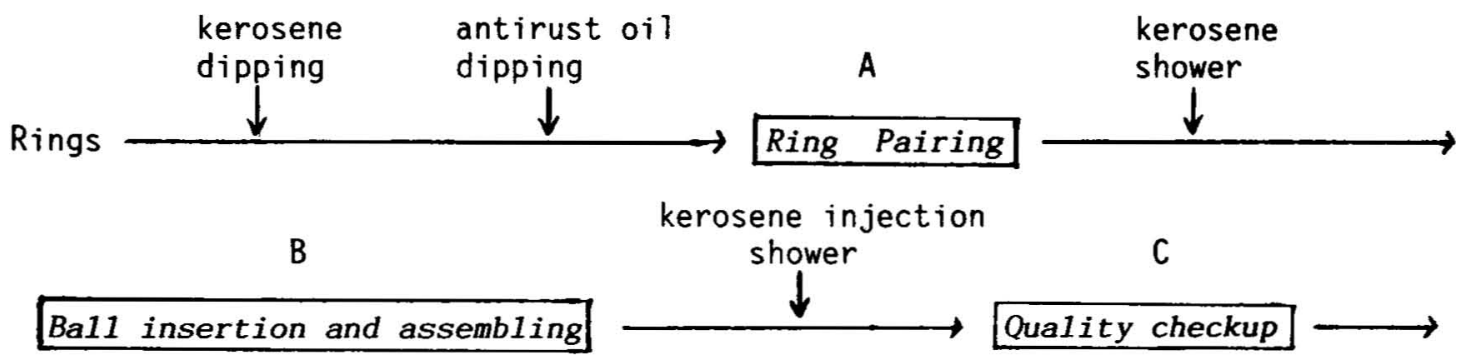

D E

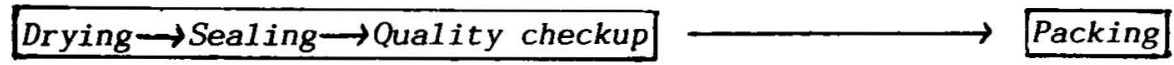

Figure 2. The work process. Workers in processes $B$ and $C$ are heavily exposed; those in processes A, D, and E are lightly exposed.

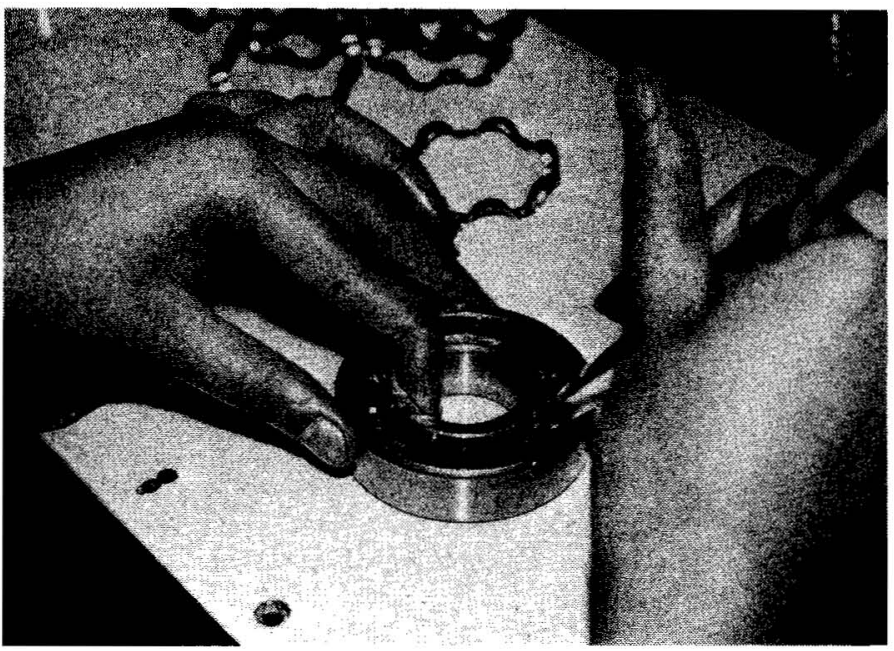

Figure 3. Process B: Workers inserting steel balls into the rings. Note that the worker's left hand is contaminated with kerosene.

The kerosene used is produced by the China Petroleum Company in Taiwan, Republic of China. It is composed of paraffin (about 60 volume \%), aromatic hydrocarbons (about 20 volume $\%$ ), and a saturated cyclic compound. The sulfur content is less than $0.1 \%$. The boiling point ranges from 150 to $235^{\circ} \mathrm{C}$, and the flash point is $38-71^{\circ} \mathrm{C}$. The octane hydrocarbon value is $25-35$. The antirust oil, produced by the Nippon Oil Company in Japan, is composed of petroleum, purified mineral oil, and unidentified antirust chemicals.

Gloves, $28 \mathrm{~cm}$ in length, made of polyvinyl chloride and plasticized with alkyl sulfonic esters of phenols are used. The heavily exposed workers wear gloves $3 \mathrm{~h}$ daily during process $\mathrm{C}$ but no inner gloves. The more lightly exposed workers wear no gloves during their work. Most of the heavily exposed workers apply cream made of glycerin, silicon oil, and a vaseline wax base before and after their daily work. The plant is air-conditioned to an average temperature of $24-25^{\circ} \mathrm{C}$.

\section{Classification of exposure categories}

Consultation with plant safety personnel allowed the exposure categories to be classified as heavy and light. Workers considered to be in the heavily exposed group were those involved with both process $B$ and $C$ within the same day. Their hands were exposed directly to kerosene about $5 \mathrm{~h}$ daily. In processes $\mathrm{A}, \mathrm{D}$, and $\mathrm{E}$ workers were less exposed because these procedures were carried out mainly by machine, and the ball-bearings were dried once after process D. Thus, among the 79 female workers in the assembling department of the ball-bearing factory, 34 were classified as heavily exposed, and the other 45 as lightly exposed. The age and duration of employment of each worker was obtained. The reference group included 263 female workers employed by a zipper-manufacturing company. Their age, income, and educational level were similar to those of the exposed group, and none was exposed to kerosene at work. The details of the two groups are shown in table 1. 
Table 1. Characteristics of the exposed (ball-bearing factory) and reference (zipper manufacturing company) groups.

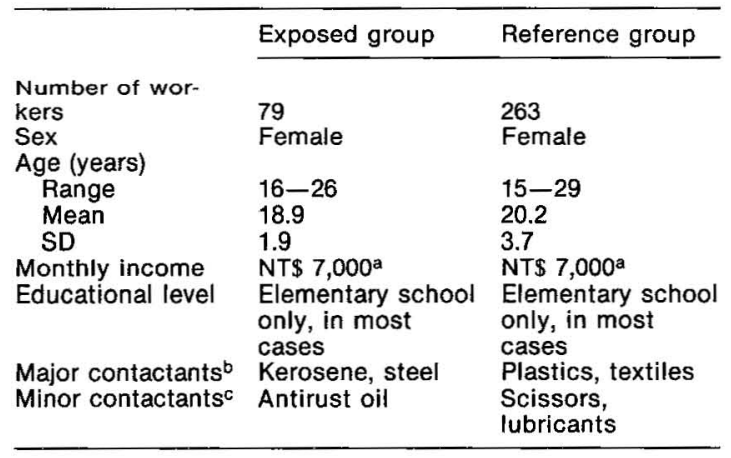

a NTS stands for new Taiwan dollars. NT\$ 7,000 is equivalent to USD 200.

b Any substances to which the workers were heavily exposed daily.

c Substances to which the workers were lightly and only occasionally exposed.

\section{Clinical observation}

Two dermatologists, each with clinical experience of more than 10 years, examined both the hands and forearms of each worker in the exposed and reference groups. Careful observation and recording of all lesions allowed their classification into the following three major groups: (i) erythema: definite erythema with or without fine desquamation over interdigital spaces; (ii) eczema: papules, papulovesicles, scaling and thickening; (iii) defatting dermatitis: pallor, dryness and fissuring. Workers with any one of these lesions were classified into the "group with dermatoses." The prevalence rate of such lesions was calculated. Statistical significance was tested with the Mantel-Haenszel procedure (4).

Then five volunteers tried to work in processes B and $\mathrm{C}$ for $3 \mathrm{~d}$ without wearing plastic gloves; the outcome was observed.

Patch tests using the National Taiwan University Hospital standard tray (7) and the American Academy of Dermatology standard tray (5) were performed on 5 of 12 exposed workers with severe eczematous lesions.

Six male workers who needed to dip their hands into a kerosene tank irregularly in a textile dyeing company were also interviewed.

\section{Results}

The prevalence rates of dermatoses among the workers with kerosene exposure and the reference group are shown in table 2. The difference between these two groups was statistically significant (Mantel-Haenszel chi square $=22.9, \mathrm{p}<0.001$ ). The prevalence rate of dermatoses was high for both the heavily exposed group and the lightly exposed group (91 and $78 \%$, respectively) and the difference between the two was not statistically significant (table 3).
Table 2. Age-specific prevalence rates of dermatoses among the exposed (ball-bearing factory) and reference (zipper manufacturing company) groups.

\begin{tabular}{|c|c|c|c|c|}
\hline \multirow{2}{*}{$\begin{array}{l}\text { Age } \\
\text { (years) }\end{array}$} & \multicolumn{2}{|c|}{ Exposed group } & \multicolumn{2}{|c|}{ Reference group } \\
\hline & $\begin{array}{c}\text { Number of } \\
\text { workers } \\
\text { examined }\end{array}$ & $\begin{array}{c}\text { Percentage } \\
\text { with } \\
\text { dermatoses }\end{array}$ & $\begin{array}{c}\text { Number of } \\
\text { workers } \\
\text { examined }\end{array}$ & $\begin{array}{c}\text { Percentage } \\
\text { with } \\
\text { dermatoses }\end{array}$ \\
\hline $\begin{array}{l}15-19 \\
20-24 \\
25-29\end{array}$ & $\begin{array}{r}59 \\
19 \\
1\end{array}$ & $\begin{array}{r}86 \\
74 \\
100\end{array}$ & $\begin{array}{r}143 \\
72 \\
78\end{array}$ & $\begin{array}{l}0 \\
1 \\
0\end{array}$ \\
\hline Total & 79 & 84 & 263 & 1 \\
\hline
\end{tabular}

Table 3. Results of the dermatologic examination of the hands with kerosene exposure.

\begin{tabular}{|c|c|c|c|c|c|c|}
\hline & \multicolumn{2}{|c|}{$\begin{array}{l}\text { Heavily } \\
\text { exposed } \\
\text { group }\end{array}$} & \multicolumn{2}{|c|}{$\begin{array}{l}\text { Lightly } \\
\text { exposed } \\
\text { group }\end{array}$} & \multicolumn{2}{|c|}{ Total } \\
\hline & $N$ & $\% c$ & $\mathbf{N}$ & $\%^{c}$ & $\mathrm{~N}$ & $\% c$ \\
\hline $\begin{array}{l}\text { Workers with } \\
\text { dermatoses } \\
\text { Erythema } \\
\text { Eczema } \\
\text { Defatting }\end{array}$ & $\begin{array}{r}31 \\
24 \\
7\end{array}$ & $\begin{array}{l}91 \\
70 \\
21\end{array}$ & $\begin{array}{r}35 \\
27 \\
5\end{array}$ & $\begin{array}{l}78 \\
60 \\
11\end{array}$ & $\begin{array}{l}66 \\
51 \\
12\end{array}$ & $\begin{array}{l}84 \\
65 \\
15\end{array}$ \\
\hline $\begin{array}{l}\text { dermatitis } \\
\text { Workers without }\end{array}$ & - & 0 & 3 & 7 & 3 & 4 \\
\hline $\begin{array}{l}\text { dermatoses } \\
\text { Total of workers }\end{array}$ & 3 & 9 & 10 & 12 & 13 & 16 \\
\hline examined & 34 & 100 & 45 & 100 & 79 & 100 \\
\hline
\end{tabular}

a Workers exposed to kerosene in processes $\mathrm{B}$ and $\mathrm{C}$ for $>5 \mathrm{~h}$ daily.

b Workers exposed to kerosene lightly and irregularly in processes $\mathrm{A}, \mathrm{D}$, and $\mathrm{E}$.

c Number of workers with or without dermatoses divided by number of workers examined multiplied by $100 \%$.

The most common finding was erythema with or without fine desquamation over the interdigital spaces. Eczema was the next most common finding (figure 4). Defatting dermatitis was also noted, but it was uncommon.

The five volunteers who worked in processes $B$ and $C$ with bare hands all developed pain on the second day. On the third day, all developed edema of the hands and blistering over interdigital spaces. The trial was stopped immediately. The blisters later ruptured, leaving a raw surface (figure 5).

The results of the patch tests were negative except for one worker, who was sensitive to $1 \%$ ammoniated mercury.

Five of the six men dipping their hands into the kerosene tank in the textile company also developed a stinging or painful sensation and erythema over the interdigital spaces.

\section{Discussion}

Kerosene is a petroleum product used as a degreasing agent for ball-bearing manufacturing. It is also used in garages or automobile repair shops, where workers have been described as often suffering from dermatitis after exposure to kerosene, gasoline, or benzene be- 


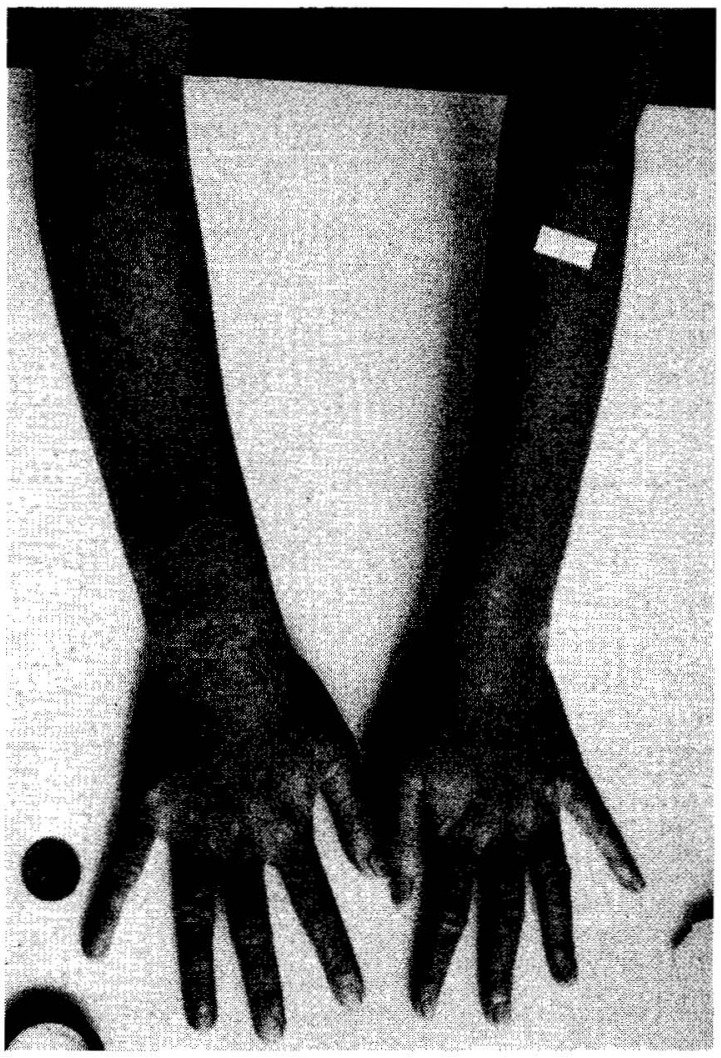

Figure 4. Eczematous lesions over the dorsa of hands and forearms.

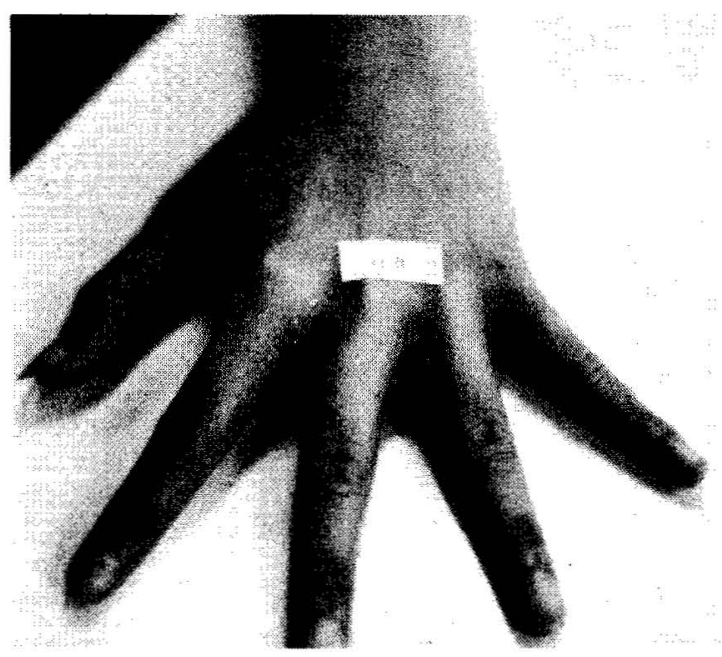

Figure 5. Raw surface with marginal desquamation over the fourth interdigital space.

cause these products àcted as skin irritants (6). However, to our knowledge, there have been few reports of kerosene dermatitis $(2,8,9)$. Tagami \& Ogino (8) reported a study of four children who developed dermatitis following contact with kerosene. Experimen- tal replication was achieved with volunteer subjects by direct application of kerosene. The experiment supported the view that kerosene dermatitis is of a primary irritant type. This view was further supported by the work of Lupulescu et al (3) on electromicroscopy, which revealed that kerosene could induce large lacunae in the horny layer and advanced cytolysis and fragmentation of tonofilaments in the spinous cells with nuclear change.

Clinical observation in this study showed, first, that most workers complained of itching, burning, or a painful sensation at the site of exposure to kerosene. Second, the prevalence rate of dermatoses among kerosene workers was high. Third, interdigital erythema with or without desquamation was the most common feature. (In addition, eczematous lesions and defatting dermatitis were also noted.) Fourth, all five volunteers who worked without wearing plastic gloves suffered painful sensations on the second day and blister formation on the third day. (The bullae subsequently ruptured to leave a raw surface.) Fifth, five of the six male workers in a textile dyeing company also had a painful sensation and developed erythema over the interdigital spaces after having their hands soaked in kerosene. All these findings support the view that kerosene might be a major irritant. In addition the painful sensation of the workers with dermatitis improved to become tolerable when antirust oil replaced kerosene in the washing of ball-bearings prior to process B in 1982. Although antirust oil was present from the beginning (figure 2), most of it was washed away after two kerosene showers during processes $\mathbf{A}$ and $\mathbf{B}$. Thus we believe that kerosene was the primary cause of the dermatoses. The fact that there was a relatively high prevalence rate $(78 \%)$ of dermatoses among workers with even light exposure indicates that kerosene is a potent irritant.

Another interesting finding is the low prevalence rate $(<1 \%)$ of hand dermatoses among the zipper workers. This rate is relatively low, compared to that reported by Agrup (1). Since most of the subjects in both groups (exposed and reference) of our study were young women who were unmarried and lived in a company dormitory, they did no housework and usually took good care of their hands. The occurrence of eczematous change among the ball-bearing workers raised the question of possible allergic contact dermatitis. Since the metal used in ball-bearings might contain chromium or nickel, we included potassium dichromate $(5 \%)$ and nickel sulfate $(2.5 \%)$ in our screen tray for patch tests. The patch tests performed on five workers from the exposed group showed they were not allergic to these metals. These workers also normally resided in the factory dormitory and did no house work such as dish washing. The conclusion was that the hand eczema was probably caused by kerosene exposure, although the possibility of allergic response to other chemicals not included in the standard tray could not be ruled out. 
Although the plasticizer of the protective glove used by the workers could be partially dissolved by kerosene, it still had some protective effect, because the five volunteers who worked in both processes B and $C$ without wearing this glove developed intolerable pain. The workers also generally agreed that the protective cream used made the skin less dry and lessened the irritation.

Furthermore, antirust oil was substituted for kerosene before process B when workers had direct contact with the agent. It was found that a combination of this substitution and the use of protective cream and gloves made the work more acceptable to the workers. However, a complete automation of the process would still be the best solution to avoid kerosene exposure.

\section{References}

1. Agrup G. Hand eczema and other hand dermatoses in south Sweden. Acta Derm Venereol 49 (1969): suppl 61.
2. Barnes RL, Wilkinson DS. Epidermal necrolysis from clothing impregnated with paraffin. Br Med J 56 (1973) 406-467.

3. Lupulescu AP, Birmingham DJ, Pinkus H. An electron microscopic study of human epidermis after acetone and kerosene administration. J Invest Dermatol 60 (1973) 33-45.

4. Mantel N, Haenszel W. Statistical aspects of the analysis of data from retrospective studies of disease. J Natl Cancer Inst 22 (1959) 719-748.

5. Robert MA. Occupational skin disease. Grune \& Stratton, New York, NY 1983, pp 148-149.

6. Schwarz L, Julipan L, Birmingham DJ. Occupational diseases of skin. Third edition. Lea and Febiger, Philadelphia, PA 1957.

7. Sun CC. Two year experience with patch testing. J Formosan Med Assoc 79 (1980) 220-229.

8. Tagami H, Ogino A. Kerosine dermatitis, factors affecting skin irritability to kerosine. Dermatologica 146 (1973) $123-131$.

9. Yamaguchi J, Tomizawa T. Dermatitis caused by kerosene. Jpn J Clin Dermatol 27 (1973) 370-371.

Received for publication: 17 September 1984. 